can readily slip through it. Oncoming solar wind particles which strike the Moon's surface become neutralized, but the equations of magnetogasdynamics are assumed to apply to the rest of the flow. The case of aligned MHD flow is worked out exactly. Comparison between theory and experiment is good.

In "The Solar Wind Problem with Fluctuations", Siseoo averages solar wind properties, including random fluctuations which are constant in the mear, over spheres of arbitrary radii centred on the Sun. Some idea of the difficulty of this problem can be obtained by observing that the equations derived are generalizations of Parker's solar wind equations. The results aro applied to various problems including the problem of the radial dependenco of the energies of fluctuations. I hope that this work will continue.

An important and illuminating paper by Russell and Thorne on the "Structure of the Inner Magnetosphero" discusses inner and outer zone electrons and protons, the plasmapause, and changes in their fluxes and positions observed during magnetic storms. An extremely convincing theoretical argument, with comparison with observations, identifies the various mechunisms at work.

The clear and well written paper on "Generation of Bow-Shock-Associated Hydromagnetic Waves" by Barnes considerably advanees the theory by Fairfield that magnotoacoustic waves upstream of the Earth's bow shock are generated by the ion-cyclotron instability from protons which are streaming away from the shock.

In the last paper, Dryer uses his wido expertise in hypersonic flow to discuss with enthusiasm, and many photographs, the hypersonic analogue of solar wind interactions with the magnetic environments of the planets, their satellites and comets. It is interesting to comparc his comments on flow round the Moon with the first paper in this issue.

In conclusion I note that the quality of printing and editing is first rate. I am delighted that there are no page charges (my collcagues in control engineering and business studies often actually got paid for publishing their papers, and can be quite humorous about "colleagues who have to pay to get their work published"); and it is pleasing to note that the price of the journal is reasonable by eurrent standards.

P. C. KENDALI.

\section{APPLIED MATHS}

Computational Methods in Partial Differential Equations By A. R. Mitchell. (Introductory Mathematics for Scientists and Engineers.) Pp. xiii +255 . (Wiley: London and New York, December 1969.) $80 \mathrm{~s}$ boards; $45 \mathrm{~s}$ paper.

\section{Numerical Methods for Partial Differential Equations} By William F. Ames. (Applications of Mathematics Series.) Pp. $\mathrm{x}+291$. (Nelson: London, 1969.) Paper 65s.

AfTer an introductory chapter in which he discusses aspects of linear algebra to be used later, Professor Mitchell deals in turn with finite difference methods of solving parabolic, elliptic and hyperbolic equations. Clear descriptions of the advantages, disadvantages, stability and convergence criteria, and the limitations of explicit and implicit methods are given. Alternating direction methods and successive over-relaxation are discussed at length. In a final chapter, the preceding theory is applied to a number of problems in fluid mechanies and elasticity. Professor Mitchell is to be congratulated in prosenting. for the first time in Finglish, such a simple and straightforward account of locally one-dimensional methods. While originating from loctures given by the author to undergraduate students of mathematies, the book demands only that the reader shall have studied those aspects of calculus and matrix theory normally found in most undergraduate courses in physical sciences and engincoring and some clementary numerical methods. Emphasis is laid on concepts and methods; relevant theorems are quoted and, very properly, the proofs are left for the reader to study in the original references if he so desires.

Professor Amos's book follow's a very similar pattern and covers almost identical material, although locally one-dimensional methods are not mentioned and the reader is given some specifie revision of the ideas of error propagation and stability in numerical methods. Some readers will prefer the rather more informal style of this book and will welcome the larger number of diagrams illustrating the text. The list of references is certainly more extensive.

Both theso volumes deserve to bo the basis of undergraduate courses in this particular aspcet of applied mathomatics because of the olear presentaticn which requires the minimum of previous mathematical knowledge, and I feel sure that many more experienced mathematicians and sciontists will use these books as works of reference for a long time to come. A. H. Craven

\section{INTRODUCTION TO THE STARS}

The Stars

Their Structure and Evolution. By R. J. 'I'tyler. (The Wykoham Science Series for Schools and Universities.) (Wykeham: London and Winchester, March 1970.) $30 s$.

I HAVe not previously looked elosely at any of the "Wykcham Scionco Series", being to some extent deterred by their declared aim "to broaden the outlook of the senior grammar school pupil and to introduce the undergraduate to the prosent state of scionce as a university study", but judging by this volume I have therefore missed a considerable amount of material useful at, a rather higher levol. In collaboration with the schoolmaster A. S. Everest, Professor Tayler has produced a book which fulfils all of its declared aims admirably, and will also provide an excellent introduction for anybody moving into research in astronomy for the first time, whatever their previous level of education.

Although writing to a somewhat less advanced standard than Schwarzschild's well known book on the same subject, Tayler covers much the same fields (with the exception of any detailed discussion of mathematical techniques) and in much the same order, commencing with chapters discussing observations and the laws of physies which determine the equations of stellar strueture, and then dealing with the main sequence, evolution right up to its final stages (including the possibility of gravitational collapse), and concluding with a chapter on possible future developments. In the later sections, the development of ideas through research is shown honestly, with gaps and uncertainties in our knowledge of these later stages of stellar evolution being clearly presented. Nothing of importance seems to have bcen omitted, while no extraneous material is included; the book provides a readable introduction to stellar structure and evolution which could do much to encourage young research workers to enter the field of theoretical astrophysies.

The lavish use of illustrations and generally high quality of the production make this volume good value, my one objection being that the use of high quality art paper is perhaps excessively extravagant in a book aimed primarily at schools and undergraduates; by the time one is in a position to pay for tho aesthetic presentation of information one is hardly likely to require an introductory text of this kind. But this in no way detracts from my whole. hearted recommendation of the book to anybody who is interestcd in the structure of the stars and possesses an elementary knowledge of physics and mathematics.

Jotrn CARIBBtn 